\title{
Towards higher aerodynamic efficiency of propeller-driven aircraft with distributed propulsion
}

\author{
Dennis Keller ${ }^{1}$ iD
}

Received: 15 February 2021 / Revised: 23 July 2021 / Accepted: 27 July 2021 / Published online: 17 August 2021

(c) The Author(s) 2021

\begin{abstract}
The scope of the present paper is to assess the potential of distributed propulsion for a regional aircraft regarding aero-propulsive efficiency. Several sensitivities such as the effect of wingtip propellers, thrust distribution, and shape modifications are investigated based on a configuration with 12 propulsors. Furthermore, an initial assessment of the high-lift performance is undertaken in order to estimate potential wing sizing effects. The performance of the main wing and the propellers are thereby equally considered with the required power being the overall performance indicator. The results indicate that distributed propulsion is not necessarily beneficial regarding the aero-propulsive efficiency in cruise flight. However, the use of wing tip propellers, optimization of the thrust distribution, and wing resizing effects lead to a reduction in required propulsive power by -2.9 to $-3.3 \%$ compared to a configuration with two propulsors. Adapting the leading edge to the local flow conditions did not show any substantial improvement in cruise configuration to date.
\end{abstract}

Keywords Distributed propulsion · Aerodynamics · Propeller · CFD

\section{Introduction}

The demand for substantial $\mathrm{CO} 2$ emission reductions in air traffic has led to an increasing research interest in air transport vehicles with electric propulsion systems. While this type of propulsion system may introduce additional complexity and challenges, its usage also opens up the design space of aircraft configurations, in particular with respect to engine integration, due to nearly scale-free efficiency of electric motors. A promising approach to benefit from this circumstance is to distribute the propulsion along the entire wing span (DP), also being referred to as distributed electric propulsion (DEP) if electric motors are utilized to drive the propulsors. Besides potential positive effects on vertical tail plane size and aircraft weight due to flight mechanics and safety considerations [1], DEP may also provide efficiency increases from an aerodynamic standpoint. Beneficial effects are thereby anticipated to originate from two sources with the first one being direct aero-propulsive efficiency increases

Dennis Keller

dennis.keller@dlr.de

1 Institut für Aerodynamik und Strömungstechnik, Deutsches Zentrum für Luft- und Raumfahrt, Lilienthalplatz 7, 38108 Braunschweig, Germany during cruise flight and the second one being indirect benefits due to improved high-lift capabilities. In cruise flight, the flexibility of DEP systems may allow for aircraft performance increases due to improved propulsor integration and hence shape optimization. Previous research efforts thereby focused on wingtip propellers. In 1984, Loth et al. investigated wingtip propellers and indicated the potential of drag reduction particularly due to the use of propellers with high disk loadings [2]. While their numerical approach was later disagreed by Miranda et al. [3], their experimental results demonstrated drag reduction potential. Miranda et al. followed a more sophisticated approach based on lifting line theory and examined the effect of various parameters on the performance of wings with wingtip mounted propellers and turbines [3]. They found a beneficial effect on the induced drag and no impact on the propeller efficiency when the propellers are mounted ahead of the leading edge. In contrast, mounting the propellers behind the wing trailing edge leads to improved propeller efficiency but no reduction in induced drag. Patterson et al. carried out wind tunnel tests with a wingtip mounted pusher turboprop. According to their results, wingtip propellers located behind the wing trailing edge may reduce the required propulsive power by $13 \%$ due to a combination of propeller efficiency increase and drag reduction [4]. More recently, Sinnige et al. found 
a drag reduction of $15 \%$ due to the utilization of a wingtip propeller at a lift coefficient of 0.5 and a thrust coefficient of 0.12 in their wind tunnel tests [5]. Moreover, Veldhuis investigated various geometric variations, such as twist distribution and propeller tilt angle, for a conventional propeller aircraft configuration [6]. Besides these direct effects, DEP systems promise increased high-lift capabilities in low speed, which in turn may yield benefits in cruise flight from wing sizing effects. With the light general aviation aircraft concept SCEPTOR, NASA tries to take advantage of this effect by utilizing high-lift propellers [7]. These propellers located along the main wing are only active in low speed and are particularly designed to increase the axial velocity behind the propellers homogeneously while minimizing power consumption and thrust $[8,9]$. With this concept, Borer et al. achieved maximum lift coefficients of over 4 with a Fowler flap that extends throughout most of the span [7].

The aim of the present work is to assess the potential of distributed propulsion for a regional aircraft with a more conservative approach. All propellers are thereby intended to primarily serve as propulsors over the entire flight envelope. Several sensitivities such as the effect of wingtip propellers, thrust distribution, and shape modifications are investigated. Furthermore, an initial assessment of the high-lift performance is performed based on take-off conditions. The results of the present study are also used for an assessment of the investigated configurations on overall aircraft level [1].

\section{Numerical methods}

In order to assess the impact of drivetrain variations on the aerodynamic and propeller performance, numerical simulations based on the Reynolds-averaged Navier-Stokes (RANS) equations have been carried out with the DLR TAU code [10]. The code relies on an unstructured finite volume approach for solving the RANS equations. For the present investigation, the implicit LU-SGS scheme was used for time stepping and a central scheme and second order Roe upwind scheme for the spatial discretization of the inviscid mean flow fluxes and the turbulent convective fluxes, respectively. The turbulence effects were modeled with the Spalart-Allmaras formulation (SA) [11] with vortical and rotational flow correction based on the Spalart-Shur correction [12]. In order to model the propeller effects, an actuator disk approach based on 2D-blade element momentum theory is implemented in $T A U$. In this way, the local forces of the propeller are calculated based on the blade properties and the local flow conditions. The blade properties are thereby given by radial distributions of the local chord length and twist as well as aerodynamic data sets reflecting the dependence of the local blade force coefficients on the angle of attack. The time averages of the resulting axial and normal forces are then imposed on the numerical domain of the RANS computation. Moreover, the forces are used to compute the integral values $T, C_{T}, C_{P}$, and the propeller efficiency $\eta_{\text {prop }}$. While the actuator disk model considers blade-induced angles of attack as described by Glauert [13], it does not explicitly include a tip loss correction as it is done in the propeller design approach (see Sect. 3). The actuator disk model of the RANS solver, in particular the consideration of $3 \mathrm{D}$ effects, therefore slightly differs from the model in the inverse propeller design approach resulting in differences in the propeller efficiencies between the two approaches. Detailed information on the actuator disk implementation can be found in $[14,15]$. The actuator disk model has shown robust behavior and good results in terms of performance parameters $\left(C_{T}, C_{P}\right)$ as well as slipstream velocity distributions (axial and circumferential) for various applications such as the simulations of conventional propellers [16], contra-rotating open rotors [17], and more recently turbofans [18].

The geometric model for the simulations consists of a main wing with integrated propulsors, whereas the fuselage and tail are neglected. The computations of the cruise flight cases were performed under trimmed conditions for balanced forces:

$$
\begin{aligned}
C_{L, \text { target }}= & C_{L, \text { eff }}=C_{L, \text { wing }}+C_{L, \text { nacelles }}+C_{L, \text { prop }} \\
-\Sigma C_{T, X a}= & C_{D}=C_{D, \text { wing }}+C_{D, \text { nacelles }} \\
& +C_{D, \text { fuselage }}+C_{D, \text { tail }} .
\end{aligned}
$$

While the contributions of the main wing, the nacelles, and the propellers are evaluated within the numerical simulations, the contributions from the fuselage and the tail are constant values based on preliminary design results. In order to fulfill the equations above, the angle of attack and the propeller blade pitch angles are iteratively modified during the simulations. Table 1 summarizes the conditions and assumptions used for the simulations.

\section{Basic geometric model}

The basis of the present investigation is the preliminary design of a regional transport aircraft carried out in the SynergIE project $[1,19]$. The aircraft is designed for 70

Table 1 Conditions for trimmed aerodynamic simulations

\begin{tabular}{ll}
\hline Parameter & Value \\
\hline Mach number & 0.55 \\
Reynolds number & $12.4 * 10^{6}$ \\
$C_{L, \text { target }}$ & 0.53 \\
$C_{D, \text { fuselage }}+C_{D, \text { tail }}$ & 0.0120143 \\
\hline
\end{tabular}


passengers and a mission range of $1000 \mathrm{~nm}$ at a cruise Mach number of $M_{c r}=0.55$. Figure 1a, b illustrates the aircraft designs with 2 and 12 propulsors, respectively.

The present assessment of the aerodynamic and propulsive performance was performed on wing-nacelle-propeller half-models (Fig. 2) derived from these conceptual aircraft designs. The performance parameters of the cruise configurations are compared to a reference case, consisting of an isolated wing with an isolated propulsor that are not interacting with each other (Fig. 2a).The propulsor and the wing of the isolated case therefore operate under freestream conditions.

The propeller shapes were obtained with an inverse design method for minimum induced loss propellers [20, 21] that is implemented via classical blade element method. Downwash and interference effects are thereby taken into account by the Prandtl tip loss factor [1, 22]. The design method was applied to all aircraft configurations using identical prescribed tip Mach numbers $\left(M_{\text {tip }}=0.796\right)$ and radial distributions of the lift coefficient. Moreover, the advance ratio was kept constant, leading to differences in Reynolds numbers and swirl losses as the propeller diameter varies with the number of propellers [1].

Table 2 summarizes the basic aircraft parameters of the configurations with two (2 eProp) and 12 (12 eProp) propellers. The main wing size was dictated by top level aircraft requirements regarding take-off and landing speeds. While the main wing of the two configurations therefore differ in size based on the conceptual design, it was kept identical in the present studies for comparison reasons.

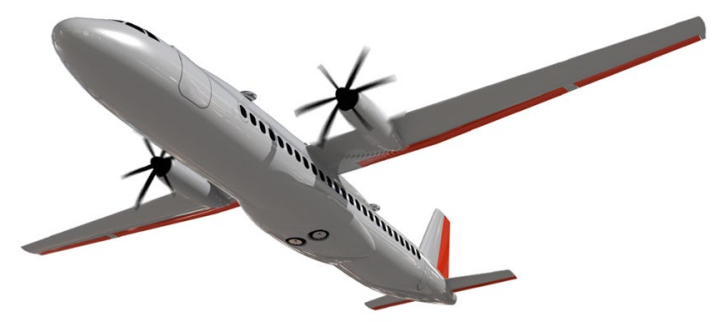

(a) 2 eProp

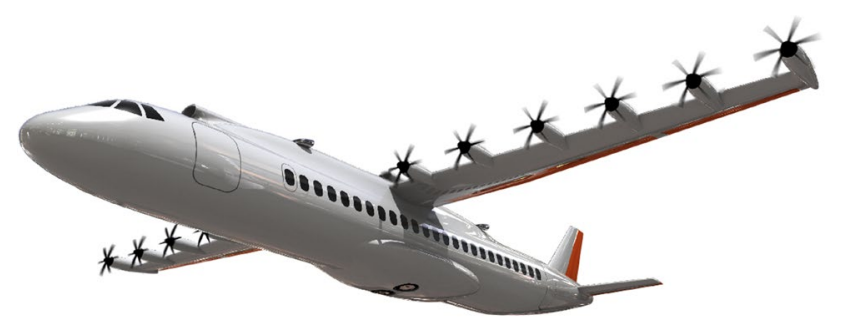

(b) 12 eProp

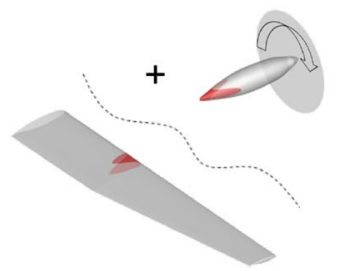

(a) isolated

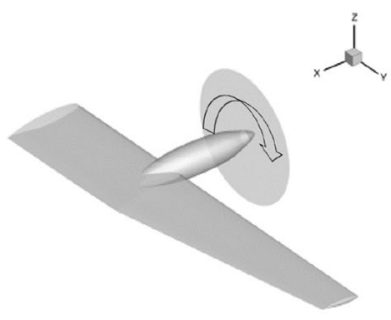

(b) 2 eProp

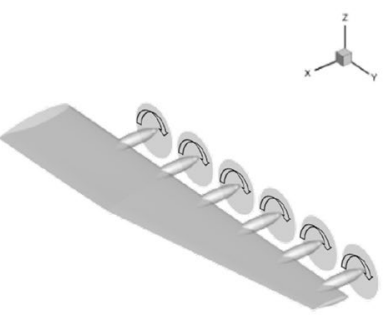

(c) 12 eProp
Fig. 2 Geometric models used for simulations

\subsection{High-lift system}

To date, a detailed high-lift design for the present configurations has not been carried out, yet. The take-off performance was investigated with a $20 \%$ chord plain flap that is deflected by $\delta_{F}=20^{\circ}$. The aileron is deflected by $\delta_{A}=10^{\circ}$. Reflecting reasonable take-off conditions based on the preliminary design, the low-speed simulations were performed with a Mach number of $M_{T / O}=0.181$ and a targeted thrust of $T_{T / O}=56.7 \mathrm{kN}$ for the full aircraft. This results in an (averaged) thrust coefficient of $C_{T}=0.44$ and $C_{T}=0.43$ for the 2 eProp and 12 eProp configuration, respectively.

\subsection{Mesh generation}

The meshes were created with a semi-automated hybrid meshing approach using the Centaur mesh generator [23]. Centaur first creates a surface grid based on triangles and quads. From the surface grid, a near-field volume mesh is

Table 2 Basic aircraft parameters of the 2 eProp and 12 eProp configuration

\begin{tabular}{lll}
\hline & 2 eProp & 12 eProp \\
\hline Reference area & $52.9 \mathrm{~m}^{2}$ & $52.9 \mathrm{~m}^{2}$ \\
Span & $25.2 \mathrm{~m}$ & $25.2 \mathrm{~m}$ \\
Aspect ratio & 12.0 & 12.0 \\
Sweep angle (leading edge) & $0^{\circ}$ & $0^{\circ}$ \\
Mean aerodynamic chord & $2.18 \mathrm{~m}$ & $2.18 \mathrm{~m}$ \\
Propeller diameter & $3.96 \mathrm{~m}$ & $1.62 \mathrm{~m}$ \\
Propeller RPM & 850 & 2080 \\
\hline
\end{tabular}

Fig. 1 SynergIE aircraft [1] 
Table 3 Basic parameters of the cruise configurations

\begin{tabular}{lll}
\hline & 2 eProp & 12 eProp \\
\hline Surface mesh points & $3.3 * 10^{5}$ & $3.4 * 10^{5}$ \\
First layer height & $1 * 10^{-6}$ & $1 * 10^{-6}$ \\
Number of layers & 50 & 50 \\
Normal cell stretching ratio & 1.225 & 1.225 \\
Volume mesh points & $2.0 * 10^{7}$ & $1.9 * 10^{7}$ \\
\hline
\end{tabular}

Table 4 Basic parameters of the take-off configurations

\begin{tabular}{lll}
\hline & 2 eProp & 12 eProp \\
\hline Surface mesh points & $5.5 * 10^{5}$ & $5.4 * 10^{5}$ \\
First layer height & $1.5 * 10^{-6}$ & $1.5 * 10^{-6}$ \\
Number of layers & 48 & 48 \\
Normal cell stretching ratio & 1.225 & 1.225 \\
Volume mesh points & $3.1 * 10^{7}$ & $2.8 * 10^{7}$ \\
\hline
\end{tabular}

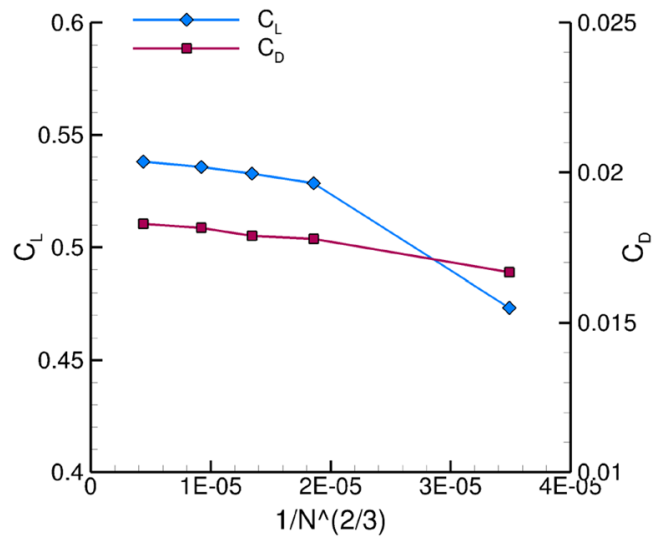

Fig. 3 Dependence of aerodynamic force coefficients on mesh discretization level at constant angle of attack $\left(\alpha=1.0^{\circ}\right)$ and constant blade pitch angle $\left(C_{T}=0.22\right)$

generated with an advancing-layer algorithm. Due to the characteristics of the surface mesh, the near-field mesh consists of prism and hexahedron stacks. Outside of the near-field mesh, the computational domain is filled with tetrahedra. Tables 3 and 4 summarize the key parameters of the meshes for the cruise and the take-off configurations, respectively.

In order to assess the accuracy of the selected meshes, a mesh refinement study has been performed. Considering the theoretical order of convergence of the selected spatial discretization scheme being two and the spatial dimension of the problem being three, Fig. 3 plots the longitudinal aerodynamic force coefficients with respect to $1 / N^{2 / 3}$. Despite the common challenges with unstructured meshes to create a mesh family with constant and consistent mesh refinement

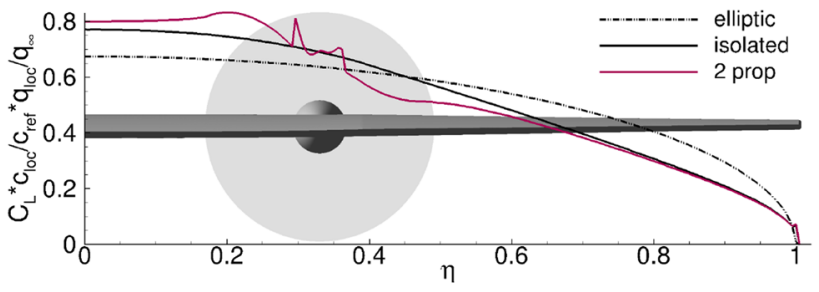

(a) 2 eProp

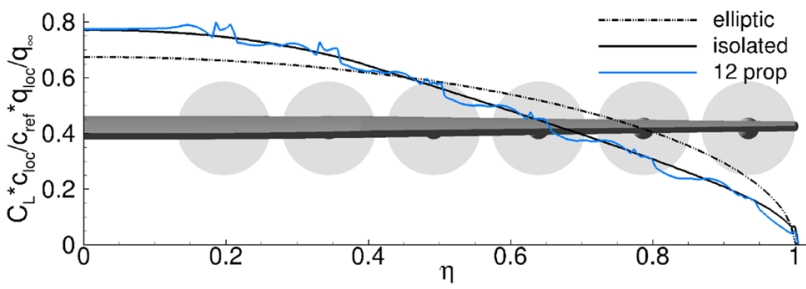

(b) 12 eProp

Fig. 4 Comparison of lift distributions under cruise conditions $\left(C_{L}=0.53\right)$

ratios, the plot indicates nearly constant gradients for the force coefficients except for the coarsest grid $\left(N=4.9 * 10^{6}\right.$ points). Accordingly, the base mesh can be considered to be within the asymptotic range. The aerodynamic performance parameter $L / D$ on the base mesh differs $0.7 \%$ from the one on the finest mesh with $109.5 * 10^{6}$ points. The propeller efficiency $\eta_{\text {prop }}$ differs by $0.003 \%$ between those two meshes.

\section{Results}

\subsection{Cruise configuration}

\subsubsection{Basic integration effects}

The comparison of the aero-propulsive performance of the configuration with 2 propulsors and 12 propulsors was carried out at a constant relative streamwise propeller position of $X / D_{\text {prop }}=-0.64$ ahead of the main wing leading edge. The total propeller disk area was kept constant for the investigated cases. The nacelle and spinner dimensions were scaled with the propeller diameter.

Figure 4 compares the lift distributions for the cases with 2 and 12 electric propulsors. As expected, both cases show an increase in local lift at the position of the propellers' upwash and a decrease in the downwash regions compared to the lift distribution of the isolated wing.

Figure 5 compares the drag distributions of the configurations with 2 and 12 electric propulsors. The distributions show locally increased drag values due to the nacelles. In close proximity to the nacelles, the drag values are reduced and partially become negative due to increased leading edge suction peaks induced by the nacelles. Besides, both 


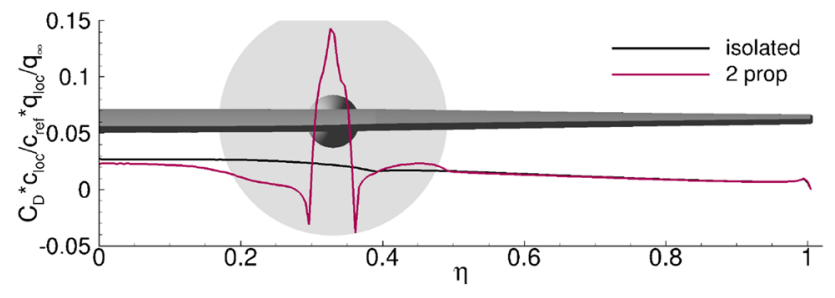

(a) 2 eProp

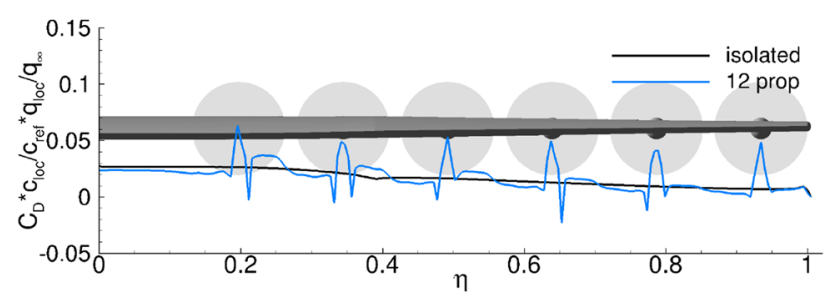

(b) 12 eProp

Fig. 5 Comparison of drag distributions

distributions generally indicate a lower local drag in the upwash regions of the propellers and a higher local drag in the downwash regions compared to the drag distribution of the isolated wing. These differences are caused by altered local angles of attack due to the propeller slipstream and the resulting tilt of the local main wing force vectors [6]. For the 2 eProp configuration, the local drag reduction in the upwash of the propeller considerably outweighs the drag increase in the propeller downwash region. That is not the case for the 12 eProp configuration. An analysis of the sectionwise integrated drag indicates that for this configuration, the local drag increase due to the propeller downwash is stronger than the local drag reduction in the propeller upwash in the inboard region. This trend reverses towards the wingtip with the local drag reduction in the propeller upwash region being stronger than the local drag increase caused by the propeller downwash, here. The varying impact of the slipstream on the local drag creation along the span of the 12 eProp configuration is thought to be mainly caused by two effects. Firstly, the main wing circulation distribution and local angle of attack distribution and thus the local force vectors' magnitude and orientation affect the impact of the slipstream on the main wing aerodynamics. In particular, the span loading gradient affects the balance of the drag reduction in the upwash region and the drag increase in the downwash region of a propeller. As the span loading gradient increases in magnitude towards the wingtip, it favors net drag reductions due to propellers with inboard up rotation that are installed in the outboard region. The 12 eProp configuration should therefore rather benefit from this effect compared to the 2 eProp configuration. Secondly, inhomogeneous propeller load distributions influence the impact of the slipstream.
Due to the global angle of attack and the upwash in front of the main wing, the downgoing propeller blades experience a higher angle of attack than the upgoing blades. The local thrust and the magnitude of the local vertical propeller force are therefore higher on the downwash side than on the upwash side. Figure 6 confirms this effect for the 2 eProp configuration with the magnitude of the local vertical force being higher on the downwash side (right hand side) compared to the upwash side. For comparison, Fig. 7 depicts the dimensionless vertical force distribution for the 12 eProp configuration. The effect of the so-called 1P-loads can be observed for all propellers. However, as the main wing's upwash decreases towards the wingtip, the asymmetric propeller forces decrease towards the wingtip as well. This can clearly be observed in Fig. 7 with the magnitude in local vertical propeller force being increased in the upwash region and decreased in the downwash region towards the wingtip. The X-component of the propeller force (thrust) distributions follows the same trend.

The spanwise distributions of the vertical and streamwise propeller forces strongly affect the local angle of attack and the magnitude of the local force vector of the main wing and therefore correlate with the main wing's drag distribution. As the absolute distance between the propellers and the main wing leading edge is smaller for the 12 eProp configuration

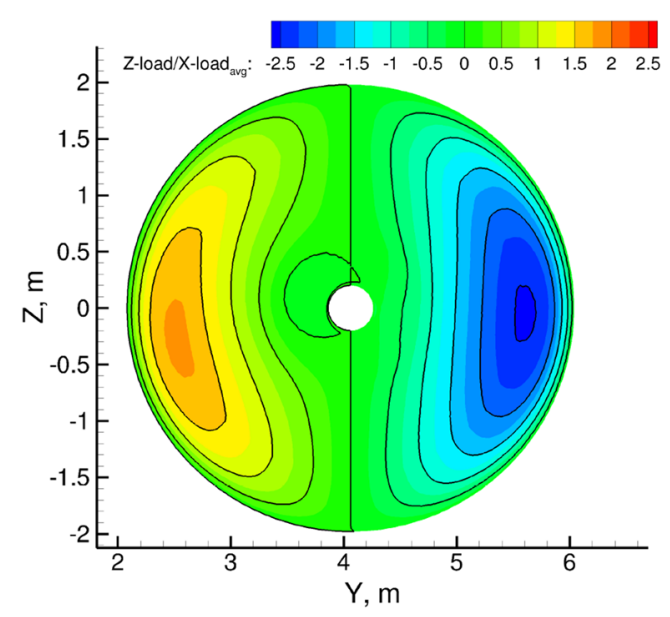

Fig. 6 Dimensionless vertical load distribution on propeller on 2 eProp propeller disk

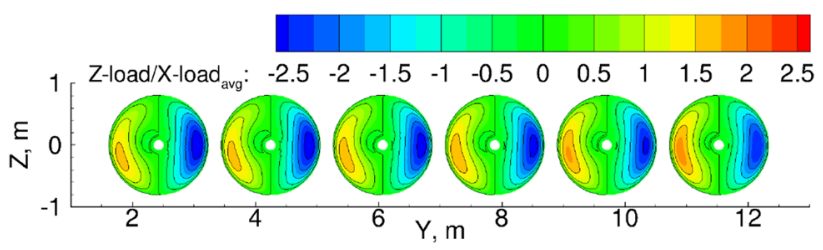

Fig. 7 Dimensionless vertical load distribution on 12 eProp propeller disk 
compared to the 2 eProp configuration, the upwash and thus the asymmetric loads are generally stronger in this case (at identical spanwise position). With decreasing circulation towards the wingtip, the asymmetric loads of the individual propellers decrease as well. Nevertheless, due to higher asymmetric loads of the propellers in the inboard and midboard region, the total drag of the 12 eProp configuration is higher compared to the 2 eProp configuration despite the drag contribution from the nacelles being smaller.

The strong effect of the streamwise propeller distance to the main wing regarding the main wing drag is illustrated for wing-propeller configurations in Fig. 8. Nacelles have not been considered for this comparison. The computations were performed at identical effective lift coefficients, including the propeller lift forces (dash-dotted lines). For comparison of the main wing's aerodynamic performance, the drag values have been corrected to constant wing lift coefficients (solid lines). The figure illustrates that at short propeller distance to the main wing, increasing the number of propellers has an adverse effect on the (corrected) wing drag (red line). In contrast, the wing drag decreases with increasing number of propellers at larger propeller distance to the wing (green line). This drag reduction is mainly caused by the wing tip propellers that are considered for configurations with more than two propellers. The figure therefore demonstrates the significance of the propeller distance to the wing on the one hand and the potentially favorable effect of distributed propulsion on the aerodynamic performance of the main wing on the other hand. The impact of the distance can be attributed to the asymmetric propeller loads, as discussed above. Locally comparing the magnitude and position of the leading edge stagnation lines at varying propeller distances confirms this effect. In contrast, the average leading edge stagnation pressure at varying distance showed little differences, indicating that the effect of the distance on the slipstream due to the change in its evolution length ahead of the main wing is rather small. Returning

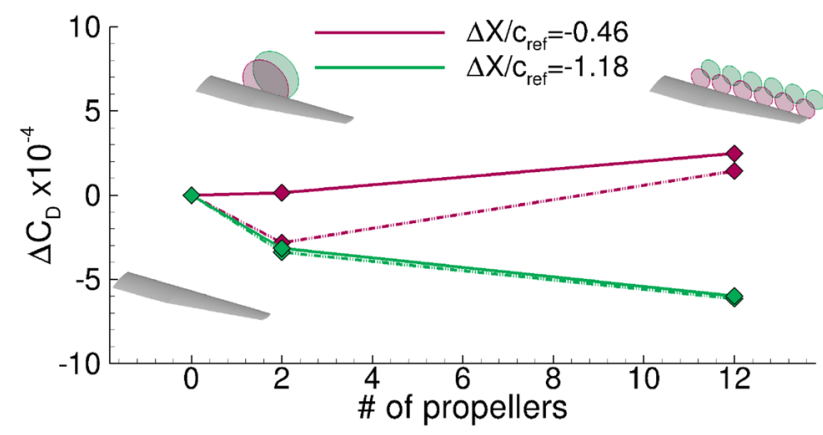

Fig. 8 Effect of number of propellers and streamwise propeller position on wing drag compared to isolated wing at trimmed effective lift coefficient (dash-dotted lines). Solid lines represent drag variations corrected for constant wing lift coefficient to the wing-nacelle-propeller configurations, Fig. 8 also confirms that the unfavorable aerodynamic performance of the 12 eProp configuration in comparison to the 2 eProp configuration can be mainly attributed to the varying absolute streamwise propeller distance to the main wing. The positive drag difference would most likely be smaller when compared to the 2 eProp configuration with identical (short) absolute distance to the main wing and it even may become negative when comparing the two (wing-nacelle-propeller) configurations at larger absolute distance.

Besides the aerodynamic performance of the main wing, the propeller efficiency is also affected by the propulsor integration. Figure 9 depicts the velocity distributions on the propeller disk for the 2 eProp configuration. Apart from the effect of the propeller, nacelle, and spinner, the axial velocity distribution (Fig. 9a) is primarily affected by deceleration ahead of the main wing. Moreover, the main wing circulation contributes to inhomogeneity of the axial velocity distribution with the axial velocity being increased in

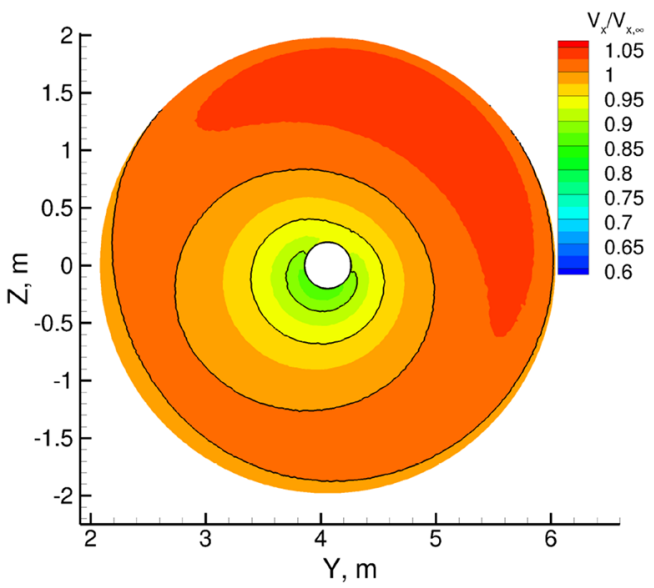

(a) Axial velocity

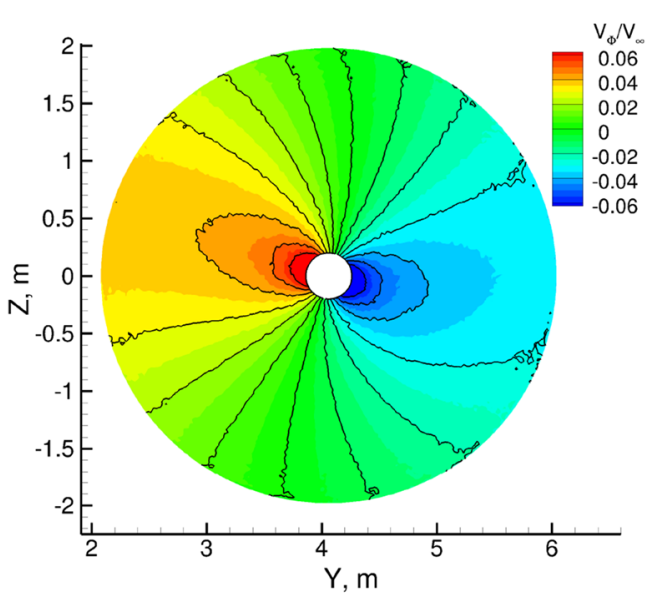

(b) Tangential velocity

Fig. 9 Velocity distribution on 2 eProp propeller disk 
the upper part of the propeller disk and decreased in the lower part. The tangential velocity distribution (Fig. 9b) is mainly affected by the main wing upwash and the global angle of attack, as discussed above. Accordingly, the tangential velocity is increased on the propeller's upwash side and decreased on the propeller's downwash side.

Figure 10 depicts the velocity distributions on the propeller disks of the 12 eProp configuration. The distributions indicate similar trends as seen for the 2 eProp configuration. However, the distributions strongly differ in intensity for the various propeller disks. While the effect of flow deceleration and main wing upwash is higher in the inboard region, it degrades towards the wingtip due to decreasing main wing thickness and circulation. Nevertheless, with $V_{x, \text { avg }} / V_{\infty}=0.986$, the average overall axial velocity of all propeller disks of the 12 eProp configuration is notably lower compared to the average velocity on the propeller disk of the 2 eProp configuration $\left(V_{x, a v g} / V_{\infty}=1.002\right)$. The lower axial velocities of the 12 eProp configuration are mainly caused by the smaller (absolute) distance between the propeller disks and the main wing leading edge.

The required propulsive power results from the thrust demand and thus the aerodynamic performance as well as the propeller efficiency with

$$
P_{\text {req }}=C_{P} \rho_{\infty} n^{3} D^{5}=\frac{C_{T} J}{\eta_{\text {prop }}} \rho_{\infty} n^{3} D^{5} .
$$

Table 5 summarizes the key performance parameters for the configurations and compares them to a configuration consisting of a wing with two isolated propulsors (Fig. 2a). The table shows that the lift-to-drag ratio (L/D) of the $12 \mathrm{eProp}$ configuration is worse compared to the 2 eProp configuration mainly due to unfavorable integration effects at the inner propulsors. The average propeller efficiency of the 12

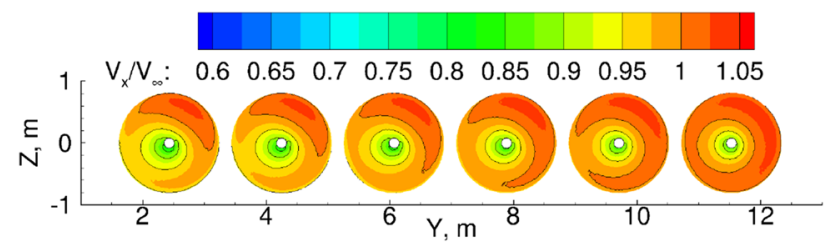

(a) Axial velocity

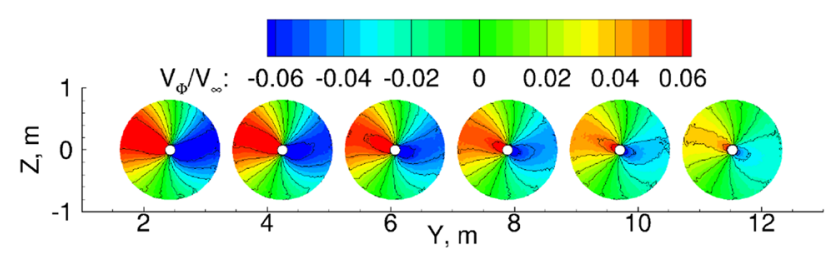

(b) Tangential velocity

Fig. 10 Velocity distribution on 12 eProp propeller disk
Table 5 Aerodynamic and propeller performance data

\begin{tabular}{lll}
\hline & 2 eProp & 12 eProp \\
\hline$L / D$ & 17.73 & 17.36 \\
$\frac{\Delta L / D}{(L / D)_{\text {iso }}}$ & $2.3 \%$ & $0.2 \%$ \\
$C_{T}$ & 0.227 & 0.230 \\
$\eta_{\text {prop }}$ & $91.7 \%$ & $93.6 \%$ \\
$\frac{\Delta \eta_{\text {prop }}}{\eta_{\text {prop }, \text { iso }}}$ & $1.5 \%$ & $3.6 \%$ \\
$P_{\text {req }}$ & $2.109 \mathrm{MW}$ & $2.106 \mathrm{MW}$ \\
$\frac{\Delta P_{\text {req }}}{P_{\text {req }, \text { iso }}}$ & $-3.9 \%$ & $-4.1 \%$ \\
\hline
\end{tabular}

eProp configuration however is notably higher compared to the one of the 2 eProp configuration. Using $V_{x, \text { avg }}$ instead of the freestream velocity for the calculation of the advance ratio, the change in averaged axial flow velocity between the 2 eProp and the 12 eProp configurations results in a $1.7 \%$ reduction of the effective advance ratio. Moreover, a reduction of the axial flow velocity is also beneficial for the $C_{T} / C_{P}$ ratio, itself. It can be therefore concluded that the increase in propeller efficiency of the 12 eProp configuration compared to the 2 eProp configuration is mainly caused by lower axial flow velocities at the propeller disks. Moreover, the increased propeller efficiencies for the 12 eProp configuration can be observed despite an opposite trend being indicated by the performance tables from the propeller design as shown in Table 6. Accordingly, the integration effect itself may be even underestimated by the comparison of the propeller efficiencies from the RANS computations.

The lower L/D ratio and the higher propeller efficiency of the 12 eProp configuration compared to the 2 eProp configuration result in a slightly lower propulsive power demand $\left(\Delta P_{r e q}=0.003 M W\right)$ for a balanced flight. Compared to the isolated case, both configurations require notably less power due to higher L/D values resulting from slipstream recovery and increased propeller efficiency that can be mainly attributed to flow deceleration ahead of the wing.

\subsubsection{Wing tip propeller}

In order to investigate the impact of wingtip propellers (WTP), the propulsors' spanwise positions of the $12 \mathrm{eProp}$ configuration were modified while remaining equidistant spacing of the propulsors.

Table 6 Propeller efficiencies

\begin{tabular}{llll}
\hline & Isolated & 2 eProp & 12 eProp \\
\hline$\eta_{\text {prop,design }}$ & $89.7 \%$ & $89.9 \%$ & $89.3 \%$ \\
$\eta_{\text {prop,RANS }}$ & $90.4 \%$ & $91.7 \%$ & $93.6 \%$ \\
\hline
\end{tabular}


Figure 11 illustrates the spanwise distributions of the sectional lift and drag forces for the 12 eProp configuration with wing tip propeller. With regard to the wingtip propeller, the lift distribution (Fig. 11a) in the outboard region shows that the main wing is only affected by the propeller's upwash, which increases the local lift, whereas the distribution does not indicate a region of lower local lift that would be accompanied to the propeller's downwash. Analogously, the drag distribution (Fig. 11b) only indicates the beneficial local drag reduction induced by the wingtip propeller's upwash but not the adverse effect of the propeller's downwash. Besides these anticipated effects and the spanwise shift of the propeller effects that is linked to the relocation of the propulsors, the distributions do not show any notable differences compared to the ones of the 12 eProp configuration without wingtip propeller. As a result, the lift-to-drag ratio is favorably affected by the wingtip propeller.

Figure 12 compares the propeller efficiencies of the 12 eProp configuration with wingtip propeller to the ones of the 12 eProp configuration without wingtip propeller. The propeller efficiencies of both configurations are highest for the propellers that are located at the wing root (propeller 1). Towards the wingtip, the efficiencies decrease. The configuration with wingtip propeller generally shows slightly lower propeller efficiencies compared to the one without wingtip propeller with the difference increasing towards the wingtip. These trends inversely correlate with the individual averaged axial flow velocities of the propeller disks $V_{x, a v g, i}$, which increase towards the wingtip. Moreover, the differences in $V_{x, \text { avg }, i}$ and as a result in $\eta_{\text {prop }}$ correlate with the differences in spanwise position of the propellers that increase towards the wingtip. Plotting the propeller efficiencies over the propellers' spanwise positions reveals identical distributions.

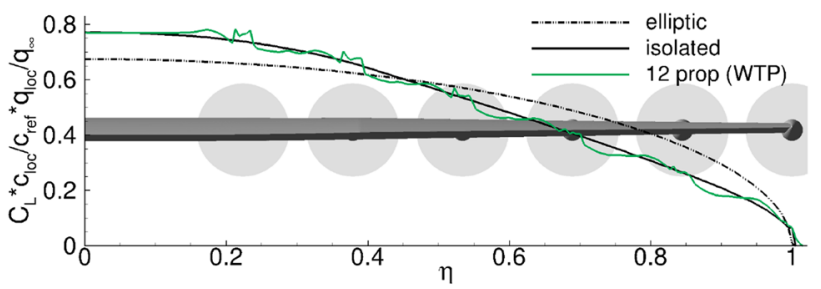

(a) Lift

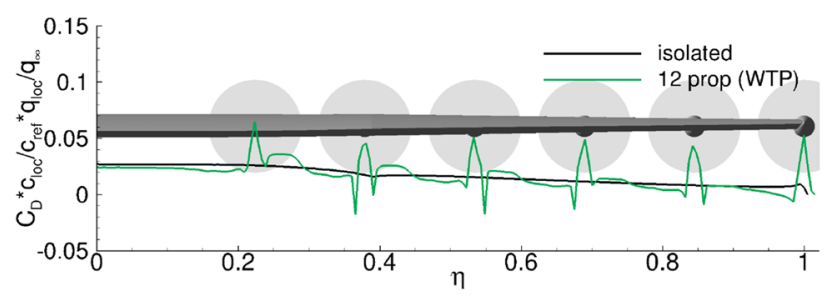

(b) Drag

Fig. 11 Spanwise force distributions for 12 eProp configuration with wing tip propeller

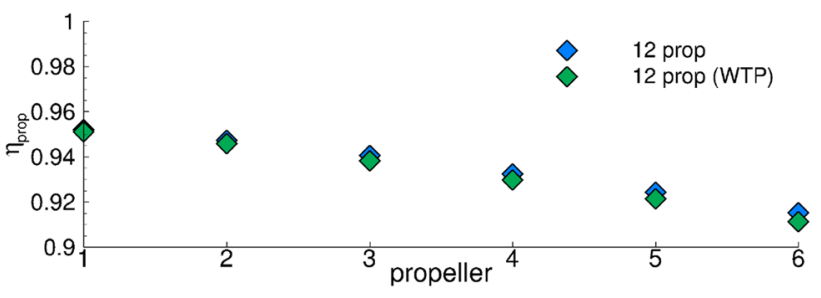

Fig. 12 Comparison of propeller efficiencies between 12 eProp without wingtip propeller and 12 eProp with wingtip propeller (propeller 1: inboard, propeller 6: outboard)

Comparing the overall averaged axial flow velocity of the two configurations indicates a slightly higher $V_{x, \text { avg }}$ for the case with wingtip propeller.

The resulting performance parameters for the configuration with wingtip propeller are shown in Table 7. The $L / D$ ratio improves by $0.8 \%$ compared to the case with the isolated wing and propulsor and is therefore also higher than the one for the 12 eProp configuration without wingtip propeller. In contrast, the averaged propeller efficiency is slightly lower than the one of the 12 eProp configuration without wingtip propeller yet yielding an increase of $3.3 \%$ compared to the case with the isolated wing and propulsor. As a result, the required propulsive power is reduced by $4.5 \%$ compared to the isolated case and thus the reduction is slightly higher than the reduction of the 12 eProp configuration without wingtip propeller.

\subsubsection{Optimization of thrust distribution}

As the impact of the wingtip propeller on the required power in the case of equal propeller settings for each configuration is rather small, the thrust distribution for the $12 \mathrm{eProp}$ configuration with wingtip propeller was adapted. An optimization study aiming at reducing the required power was therefore carried out. The six propeller pitch angles thereby where the design parameters that were individually optimized. Again, the balanced flight condition in terms of drag and thrust at the target lift coefficient was a prerequisite.

Table 7 Aerodynamic and propeller performance data for 12 eProp configuration with wingtip propeller 
Figure 13a depicts the evolution of the drag coefficient with respect to the thrust share of each of the six propellers in the course of the optimization. It shows that the thrust share of the propellers two and three, which are located in the inboard and midboard region, decrease towards lower drag coefficients. In contrast, the thrust share of propeller five and six increases. It is anticipated that these trends would continue to lower drag coefficients, if the optimization goal was to minimize drag. The analysis in Sect. 4.1.2 however indicates that the propeller efficiency decreases towards the wingtip, affecting the required propulsive power and thus the evolution of the optimization results. This is shown in Fig. 13b, which illustrates the evolution of the (required) power coefficient with respect to the thrust share. The plot indicates similar trends as seen for the drag coefficient. However, these trends are less distinct. The minimum in required power appears to be found for a thrust share of $T_{2} / T_{\text {total }}=12.7 \%$ and $T_{6} / T_{\text {total }}=20.8 \%$ for the second and sixth propeller, respectively. The thrust shares of propeller three and propeller five are $T_{3} / T_{\text {total }}=15.3 \%$

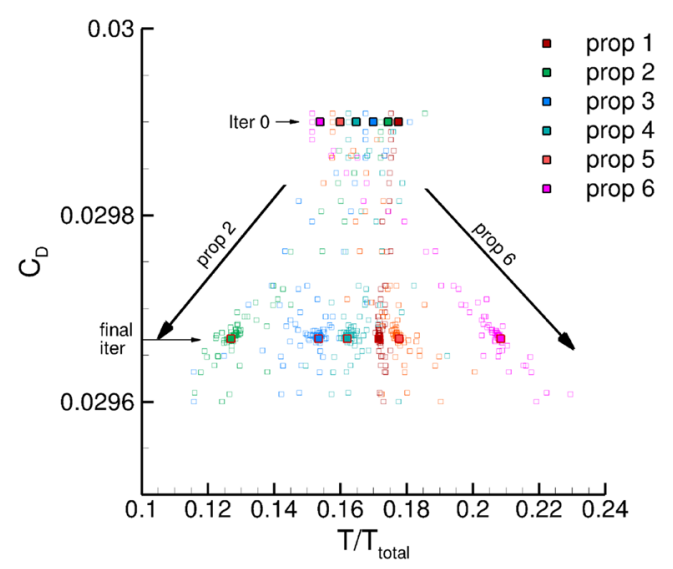

(a) Drag coefficient

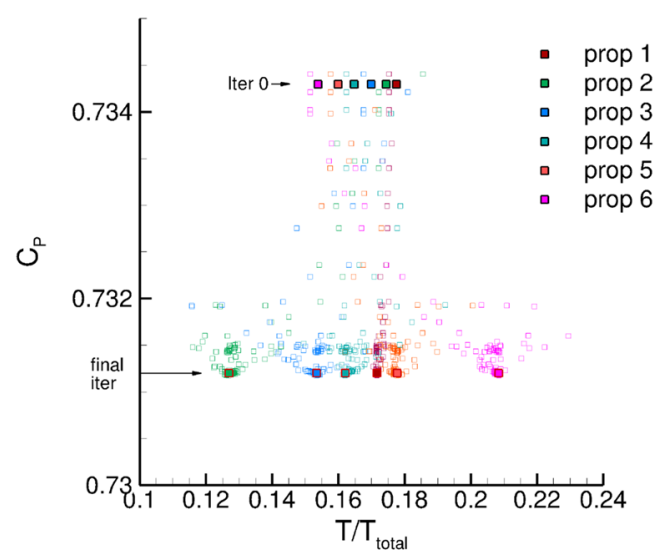

(b) Power coefficient

Fig. 13 Optimization results showing influence of thrust distribution on performance parameter and $T_{5} / T_{\text {total }}=17.8 \%$. This thrust distribution improves the $\mathrm{L} / \mathrm{D}$ ratio by $0.7 \%$ compared to the case with baseline propeller settings. As the averaged propeller efficiency is lower in case of optimized thrust distribution, the net reduction in required propulsive power is $-0.4 \%$. Table 8 compares the key performance parameters of the optimized thrust case with the ones of the isolated case.

\subsubsection{Leading edge adaptation}

In order to further reduce the required propulsive power of the 12 eProp cruise configuration, a modification of the leading edge was considered. The basic idea thereby is to reduce the airfoil and/or induced drag by adapting the leading edge deflection and thickness to the local flow conditions impacted by the propeller slipstream. Figure 14 illustrates the leading edge parametrization by means of two airfoil sections being located inboard and outboard of each propulsor.

Results from a preliminary study on a simplified geometry consisting of a main wing section with one nacelle and propeller (Fig. 15) indicated potential for performance improvement. The preliminary study was performed at a target lift coefficient of $C_{L, \text { target }}=0.6$.

Figure 16 depicts the effect of leading edge modification on the lift-to-drag ratio distribution for the simplified geometry. The black dash-dotted lines indicate the position of the airfoil section being modified. On the inboard side of the propulsor (Fig. 16a), positive leading edge deflection of up to $\delta_{L E}=10^{\circ}$ (orange line) leads to a L/D increase over a wide range of the inner wing part. For $\delta_{L E}=20^{\circ}$ (red line), the $\mathrm{L} / \mathrm{D}$ peak outside of the propeller disk area is stronger, whereas the L/D distribution behind the propeller disk is partially lower compared to the baseline case without deflection (BSL). On the outboard side of the propulsor (Fig. 16b), neither a positive nor a negative leading edge deflection angle could improve the local L/D distribution. Modifying the leading edge deflection angle had a rather minor impact

Table 8 Aerodynamic and propeller performance data for 12 eProp configuration with wingtip propeller and optimized thrust distribution

\begin{tabular}{ll}
\hline & $\begin{array}{l}12 \text { eProp w/wingtip propeller } \\
\text { and optimized thrust distribu- } \\
\text { tion }\end{array}$ \\
\hline$L / D$ & 17.6 \\
$\frac{\Delta L / D}{(L / D)_{\text {iso }}}$ & $1.5 \%$ \\
$\eta_{\text {prop }}$ & $93.0 \%$ \\
$\frac{\Delta \eta_{\text {prop }}}{\eta_{\text {prop }, \text { so }}}$ & $2.9 \%$ \\
$P_{\text {req }}$ & \\
$\frac{\Delta P_{\text {req }}}{P_{\text {req }, \text { iso }}}$ & $2.088 \mathrm{MW}$ \\
\hline
\end{tabular}


Fig. 14 Leading edge parametrization in airfoil sections inboard and outboard of the nacelle (not visible)

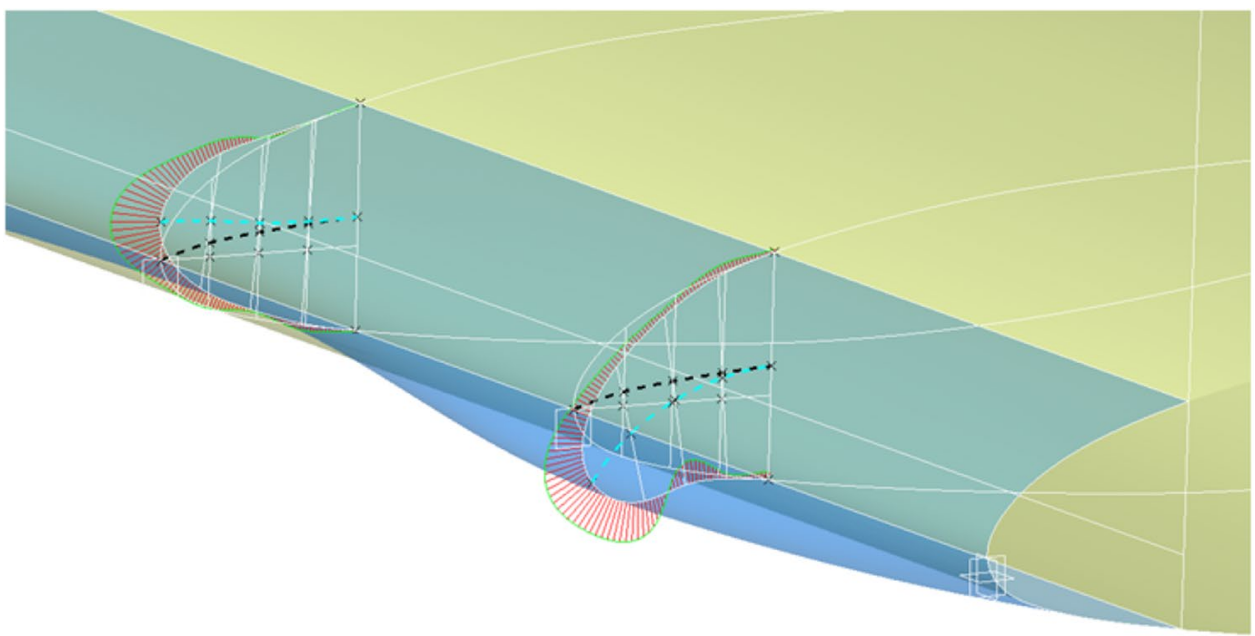

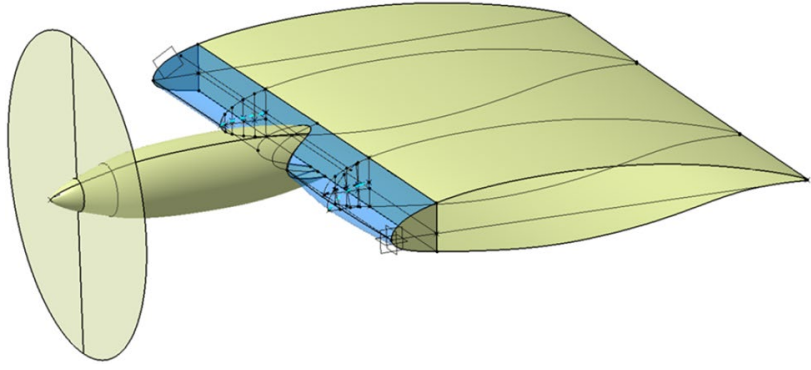

Fig. 15 Geometry of simplified model

on the local lift distribution. The impact on the induced drag is therefore anticipated to be small as well.

Based on the results of the preliminary study, leading edge modifications were implemented on the 12 eProp configuration. Figure 17a compares the lift distributions of selected cases to the baseline case (black line). Both cases with modified leading edge have a leading edge deflection of $\delta_{L E}=10^{\circ}$ in the upwash regions of the propellers. While the nose thickness is unchanged for the first one (blue line), the nose thickness of the second case was reduced by $20 \%$ in the upwash regions (green line). The plot reveals that the modifications have little effect on the lift distribution. However, a slight increase in local lift can be observed in the downwash regions of the propellers. The comparison of the drag distributions (Fig. 17b) indicates minor reductions in local drag in some of the upwash regions, particularly of propeller two and three. The reductions appear to be larger in the case with reduced leading edge thickness. However, these slight drag reductions are counteracted by drag increases in the downwash regions of the propellers. Again, the effect appears to be stronger in the case with reduced leading edge thickness. As a result, the net effect of the leading edge modification is negligible for the cruise configuration. Nevertheless, initial results of the take-off configuration confirm the expected positive effect on the high-lift performance.

\subsection{Reduced wing size}

The increased low-speed performance eventually leads to a reduced main wing size. Reducing the main wing size
Fig. 16 Impact of leading edge deflection on local lift-to-drag ratio

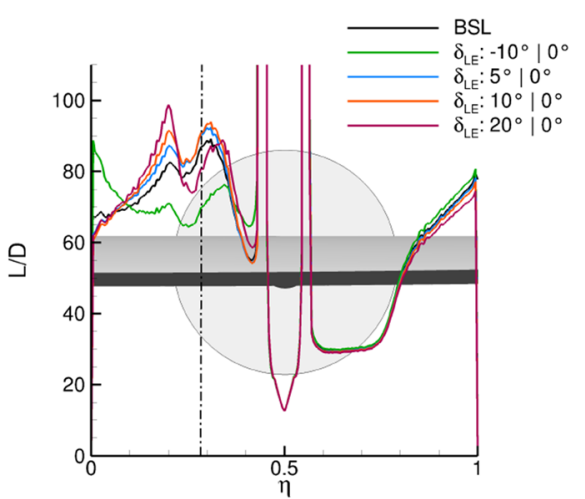

(a) Modification via inboard section only

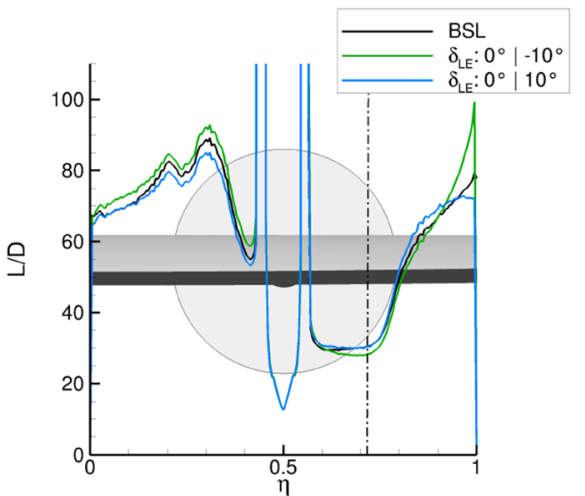

(b) Modification via outboard section only 


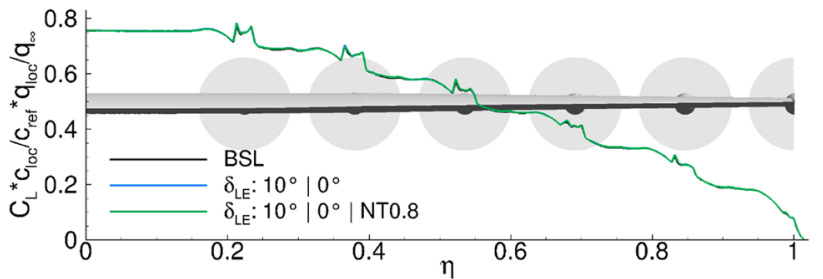

(a) Lift distribution

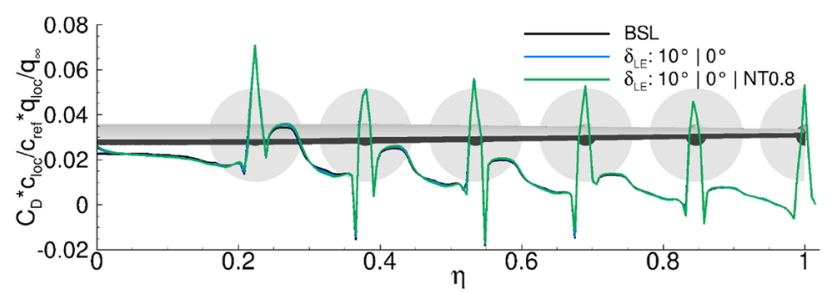

(b) Drag distribution

Fig. 17 Impact of leading edge deflection on local force distribution of the 12 eProp configuration (with WTP)

improves the aerodynamic performance in various ways. Firstly, the main wing will experience higher angles of attack during cruise flight, which typically leads to improved liftto-drag ratios for conventional airfoils and representative flight conditions. Secondly, the wetted surface and thus friction drag is reduced.

In order to make an initial estimation of the impact of a wing size reduction on the performance in cruise flight, a potential wing size reduction of $10 \%$ due to the improved high-lift performance is assumed. Accordingly, simulations of the 12 eProp configuration with wingtip propeller and with a $10 \%$ reduced chord length were performed. Figure 18a illustrates the influence of the wing size reduction on the lift-to-drag ratio (L/D) of the main wing (with nacelles) depending on the lift coefficient. The black line represents the lift-to-drag ratio of the case with initial wing size. The black diamond with red outline thereby indicates the target lift coefficient. At identical conditions, reducing the wing size causes an increase in the target lift coefficient for level flight. Neglecting scaling effects and assuming an identical aerodynamic behavior of the smaller wing would move the operating point on the black line beyond the maximum and eventually reduce the lift-to-drag ratio (red X). This change in $\mathrm{L} / \mathrm{D}$ would correspond to the effect caused by the airfoils operating at higher angles of attack, which is in this particular case unfavorable. Compared to that, 3D-RANS computations of the case with reduced wing size yielded a notably improved aerodynamic behavior as shown by the green line and in particular for the target lift coefficient (green diamond with red outline). $70 \%$ of the total drag reduction is thereby caused by a reduction in friction drag with the remaining part being related to pressure drag. It shall be noted that the drag is affected by a slight change in the lift distribution that occurs due to the wing size reduction.

Figure $18 \mathrm{~b}$ depicts the lift-to-drag ratio over the cruise speed at $1-\mathrm{g}$ load factor considering a drag penalty for the fuselage and tail. Again, assuming an identical aerodynamic behavior (i.e., with scaled drag penalty) for the case with reduced wing size would lead to a shift of the initial L/D curve (black line) towards higher velocities. Now, assuming a constant drag penalty would cause a reduction in the $\mathrm{L} / \mathrm{D}$ values. The gray line describes the result, when a constant drag penalty for fuselage and tail and otherwise identical aerodynamic behavior is considered. Compared to that, the L/D values of the case with reduced wing size resulting from 3D-RANS simulations (green line) are generally higher. The diamonds with red outline indicate an improved lift-to-drag ratio due to the wing size reduction at target cruise speed.

Table 9 summarizes the main performance parameters for cruise flight conditions. The chord-length reduction leads to a further increase in the lift-to-drag ratio by about $2.1 \%$ compared to the corresponding case with $100 \%$ chord length, yielding a $2.9 \%$ increase compared to the isolated configuration. Moreover, the propeller efficiency slightly increased by additional $0.2 \%$. As a result, the 12 eProp configuration with wingtip propeller and $90 \%$ chord length requires $-6.8 \%$ less propulsive power compared to the isolated case mainly due to the improved aerodynamic performance of the main wing.
Fig. 18 Influence of $10 \%$ chord-length reduction on liftto-drag ratio under cruise flight conditions

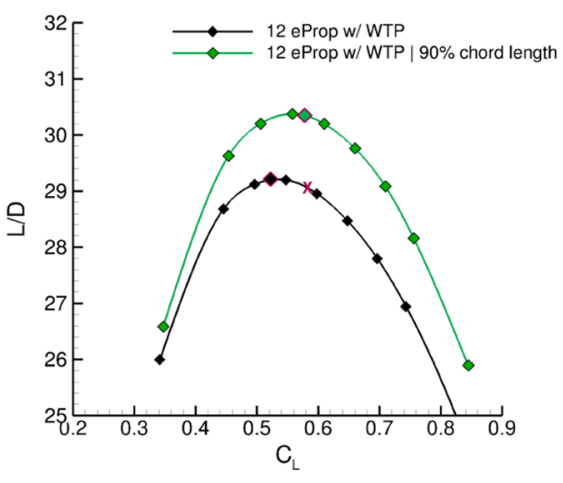

(a) Wing-nacelles

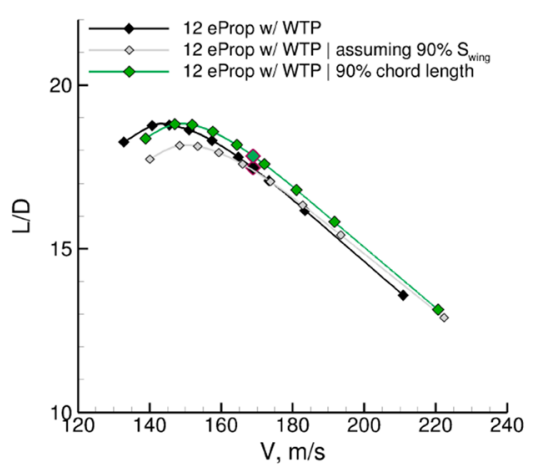

(b) Wing-nacelles considering constant drag contribution from fuselage and tail 
Table 9 Aerodynamic and propeller performance data for 12 eProp configuration with wingtip propeller

\begin{tabular}{ll}
\hline & $\begin{array}{l}\text { 12 eProp w/wingtip } \\
\text { propeller / 90\% chord } \\
\text { length }\end{array}$ \\
\hline$L / D$ & 17.84 \\
$\frac{\Delta L / D}{(L / D)_{\text {iso }}}$ & $2.9 \%$ \\
$\eta_{\text {prop }}$ & $93.5 \%$ \\
$\frac{\Delta \eta_{\text {prop }}}{\eta_{\text {prop,iso }}}$ & $3.5 \%$ \\
$P_{\text {req }}$ & $2.047 \mathrm{MW}$ \\
$\frac{\Delta P_{\text {req }}}{P_{\text {req,iso }}}$ & $-6.8 \%$ \\
\hline
\end{tabular}

Assuming the beneficial effect of thrust redistribution can be likewise applied in the case of a reduced chord length, the power reduction would change to $-7.2 \%$.

\subsection{Effect of distributed propulsion on take-off performance}

In a first step to assess the impact of distributed propulsion on the high-lift performance, the 2 eProp and 12 eProp (with WTP) configurations were investigated with a plain flap.

Figure 19 illustrates the surface pressure coefficient distribution for the main wing upper side of the take-off configurations with $\delta_{F}=20^{\circ}$ at $\alpha=6^{\circ}$. In the case of the 2 eProp configuration without thrust, the flow is completely separated from the flap except for a small region downstream of the nacelle (Fig. 19a). With thrust (Fig. 19b), the pressure coefficient distribution is altered over a wide range of the wing. Inboard of the nacelle, the propeller causes a considerable increase in the leading edge suction peak with the flow above the flap remaining separated. In the downwash region of the propeller, the slipstream leads to a decrease in the local angle of attack, causing the leading edge stagnation line to move onto the upper side of the main wing locally. The reduction in the local angle of attack in conjunction with the locally increased flow momentum results in the attachment of the flow to the flap and consequently to the development of a flap suction peak. While this particular effect is rather local, the increase in wing circulation due to the propeller slipstream affects the regions adjacent to the propeller, raising the local angle of attack there as well and thus increasing the leading edge suction peak. The flow above most of the flap as well as the aileron remains however separated. In the case of the 12 eProp configuration with thrust, the effects of the propeller slipstream as seen for the 2 eProp configuration can be observed for each propeller. The distribution of thrust also leads to five downwash regions with mostly attached flow on the flap and the aileron and therefore to a significant reduction in flow separation.

A comparison of the lift distributions at $\alpha=6^{\circ}$ illustrates the impact on the lift creation capabilities. Due to thrust, the

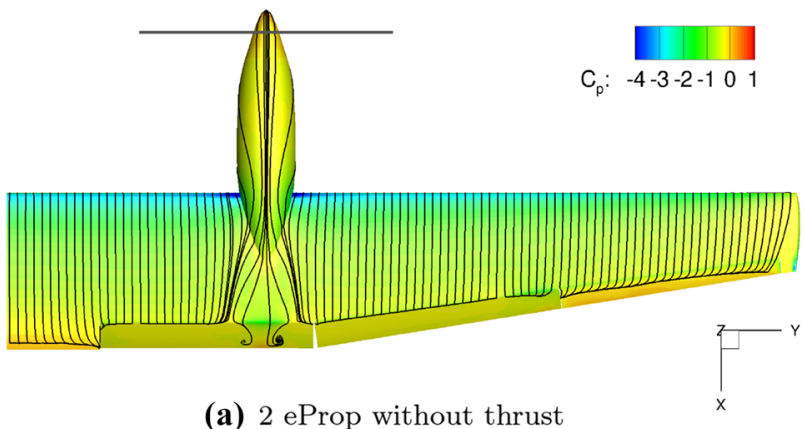

(a) 2 eProp without thrust

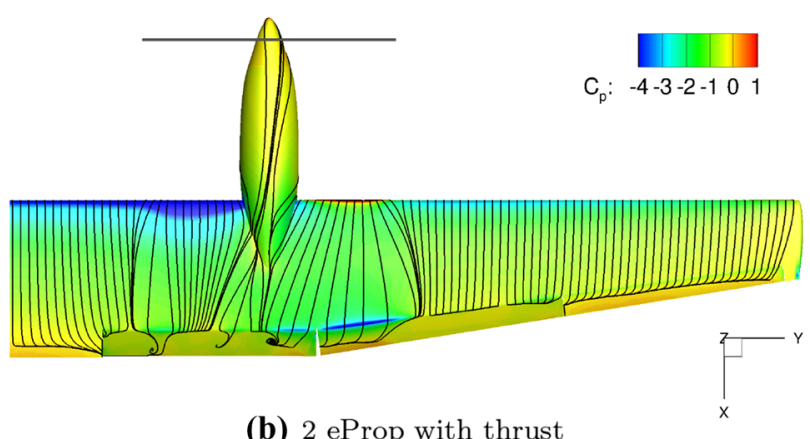

(b) 2 eProp with thrust

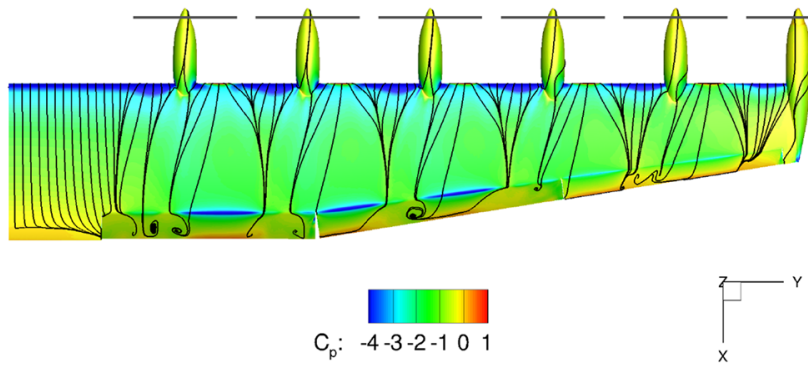

(c) 12 eProp with thrust

Fig. 19 Surface pressure distribution and skin friction lines of takeoff configurations at $\alpha=6^{\circ}$

local lift of the 2 eProp configuration is notably increased in the region of the propeller. The lift increase is thereby lower in the downwash region of the propeller due to the reduced angle of attack and the resulting shift of the leading edge stagnation line to the upper side of the wing. In proximity to the propeller, in particular at the wing root, the local lift is also raised, whereas the outboard region of the main wing remains rather unaffected. In the case of the $12 \mathrm{eProp}$ configuration, the lift is raised due to thrust over the entire wingspan. Furthermore, the difference in local lift between the upwash and downwash regions of the propellers appear to be smaller (Fig. 20).

Figure 21 visualizes the flow field above the main wing of the 12 eProp take-off configuration with thrust at $\alpha=15^{\circ}$. The illustration indicates rough flow conditions over the entire wing span, particularly in the upwash region of the propellers. The upwash and nacelle flow of one propeller 


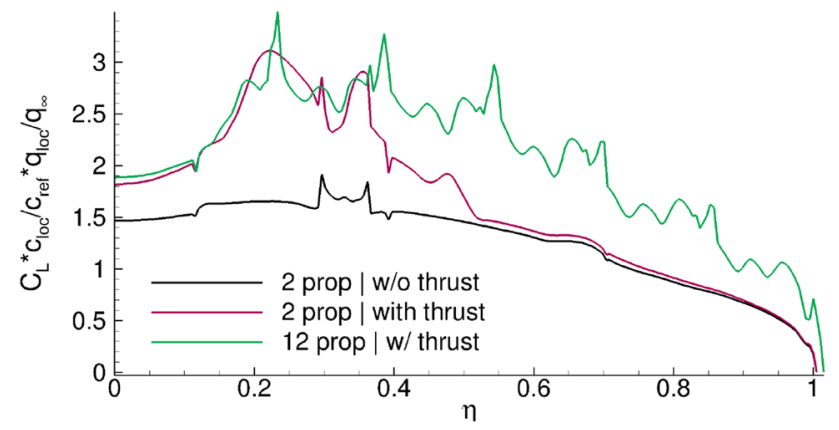

Fig. 20 Comparison of lift distributions of take-off configurations at $\alpha=6^{\circ}$

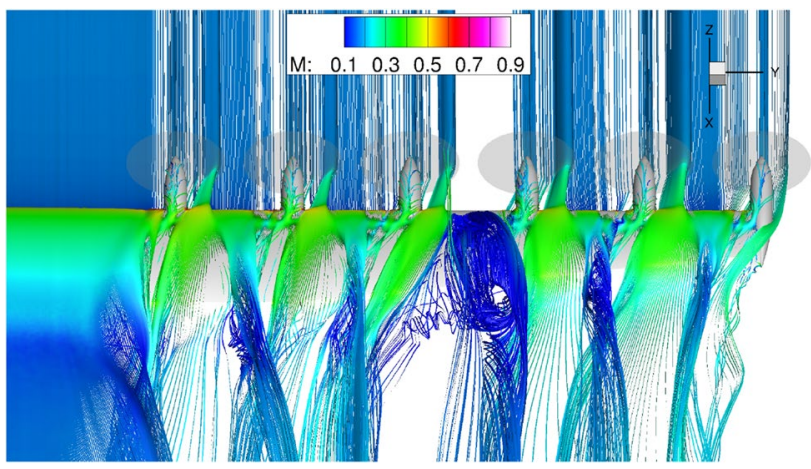

Fig. 21 Flow visualization by means of streamlines colored by Mach number in post-stall $\left(\alpha=15^{\circ}\right)$ of 12 eProp take-off configuration with thrust

thereby interacts with the downwash of the adjacent one causing rotational flow above the main wing. The flow interaction eventually leads to leading edge separation, beginning in the region between propulsors three and four.

The effect of thrust on the lift creation of the presented configurations can be observed over the entire range of investigated angles of attack (Fig. 22, "with thrust" vs. "no thrust"). At $\alpha=6.0^{\circ}$, the airframe's lift coefficient $\left(C_{L}\right)$ of the 2 eProp configuration increases by $\Delta C_{L}=0.38$ due to thrust. The lift coefficient of the 12 eProp configuration with thrust is further increased by $\Delta C_{L}=0.43$ compared to the one of the 2 eProp configuration. Considering the additional lift force that is contributed by the propellers, themselves, the effective lift coefficients $\left(C_{L, \text { eff }}\right)$ of the 2 eProp and 12 eProp configurations with thrust are $\Delta C_{L, e f f}=0.46$ and $\Delta C_{L, \text { eff }}=0.90$ higher compared to the 2 eProp configuration without thrust. The maximum effective lift coefficient of the 12 eProp configuration with thrust is $\Delta C_{L, \max , \text { eff }}=0.42$ (18\%) higher compared to the 2 eProp configuration with thrust and $\Delta C_{L, \text { max,eff }}=1.14(72 \%)$ higher than the one of the 2 eProp configuration without thrust.

As indicated by Fig. 21, the boundary layer originating from the nacelles notably interacts with the fresh boundary

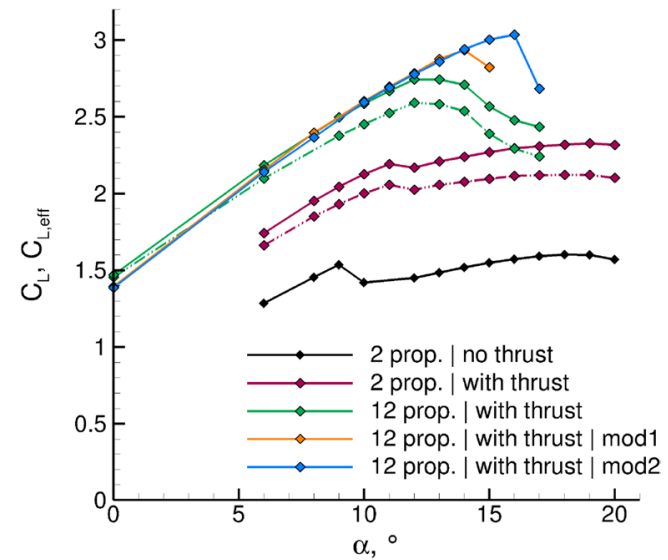

Fig. 22 Lift curves $\left(C_{L}\right.$ : dash-dotted lines $\mid C_{L, \text { eff }}$ : solid lines) of takeoff configurations. $C_{L}$ thereby considers the lift forces of the wing and nacelles, whereas $C_{L, e f f}$ also includes the lift forces of the actuator disk (propeller). Mod1: with adapted propulsor integration I $\bmod 2$ : with adapted propulsor integration and leading edge modification $\left(\delta_{L E}: 10^{\circ} / 0^{\circ}\right)$ as discussed in Sect. 4.1.4

layer that is created at the wing leading edge in the propellers' upwash regions causing the leading edge stall to occur earlier. Adapting the propulsor integration by lowering the vertical nacelle positions ("mod1") therefore has a beneficial effect on $C_{L, \max , e f f}$ as shown in Fig. 22. Moreover, the leading edge modification as described in Sect. 4.1.4 indicates a further delay in stall onset ("mod2"). As a result, the maximum effective lift coefficient is raised by additional $\Delta C_{L, \text { max } \text {,eff }}=0.29$ to $C_{L, \text { max } \text { eff }}=3.04$ (blue line). $\Delta C_{L, \text { max }, \text { eff }}=0.19$ of the increase can be thereby attributed to the adapted propulsor integration alone (orange line).

Obviously, the potential benefits of improved high-lift performance to the overall aircraft design will also depend on the performance during approach and landing. Moreover, it will eventually be a question of certification requirements.

\section{Conclusions}

A numerical study on the potential of distributed electric propulsion with regard to the aero-propulsive efficiency has been carried out for a novel regional aircraft design on the basis of a RANS-approach with actuator disks. The configuration with distributed electric propulsion (12 eProp) has been compared to a configuration with two propellers (2 eProp) and a reference case consisting of an isolated wing with isolated nacelle and propeller. Furthermore, several design details and parameters such as wingtip propellers, thrust redistribution, and leading edge adaptation have been investigated. While the study focused on the cruise configuration, an initial estimation of the low-speed performance 
was undertaken based on a high-lift system consisting of plain flaps and take-off conditions.

The study leads to following conclusions:

- The comparison generally shows that due to the potentially close coupling of propellers and main wing, it is insufficient to only analyze drag (or net drag) for the aerodynamic/aero-propulsive assessment of DEP configurations. Instead the performance of the propellers have to be considered, for example by evaluating the required propulsive power.

- Increasing the number of propellers from two to twelve propellers initially appears unfavorable for the aerodynamic performance of the present configuration. The main reason is thought to be the shorter absolute propeller distance to the wing at identical relative distance $X / D_{\text {prop }}$, which causes higher asymmetrical propeller forces. The asymmetry of the forces adversely affects the aerodynamic performance. Simulations of reduced wing-propeller models with identical absolute propeller distances confirm that the effect of the number of propellers on the aerodynamic performance strongly depends on the streamwise propeller distance. While it appears unfavorable at small distance, it becomes beneficial at larger propeller distance.

- The increase of the number of propellers from two to twelve has a favorable impact on the average propeller efficiency. Again, the streamwise propeller distance is thought to be the main reason. While decreasing the streamwise propeller distance to the main wing has an adverse effect on the aerodynamic performance of the main wing, it has a favorable effect on the propeller performance due to flow deceleration ahead of the main wing. The net effect from the impact on the aerodynamic performance and the propeller efficiency due to the change in the number of propellers is negligible for the present baseline configuration.

- Placing the outer propellers of the 12 eProp configuration at the wingtips reduces the required propulsive power by $-0.4 \%$ compared to the isolated case if the propeller settings are not optimized. The aerodynamic performance thereby improves slightly more, whereas the average propeller efficiency is slightly reduced.

- Optimizing the thrust distribution of the 12 eProp configuration with wingtip propeller by adjusting the propeller blade pitch angles further reduces the required propulsive power by $-0.4 \%$ mainly due to a shift of the thrust creation towards the wingtip. Again, the beneficial impact on the aerodynamic performance of the main wing is thereby counteracted by an adverse effect on the propeller efficiency.

- The modification of the leading edge in order to adapt to the impact of the propeller slipstreams on the main wing onset flow did not yield any substantial improvement for the cruise configuration. While positive trends can be observed for a wing section, the implementation on the full wing was not successful to date.

- A first assessment of a wing size reduction that may become possible due to improved high-lift performance yields a decrease in the required propulsive power by $-2.3 \%$ when assuming a potential high-lift performance improvement of $11 \%$. This decrease in required propulsive power emerges despite the fact that the initial wing already operates close to its maximum L/D under cruise conditions.

- The investigation of a plain flap high-lift configuration with $20^{\circ}$ flap deflection at take-off conditions indicates substantial potential for lift augmentation for this configuration due to distributed propulsion. The effective maximum lift coefficient (including propeller forces) is raised by $\Delta C_{L, \text { max }, \text { eff }}=0.42(18 \%)$ due to the utilization of twelve propellers instead of two. Compared to the 2 eProp configuration without thrust, the effective maximum lift coefficient of the 12 eProp configuration with thrust is increased by $\Delta C_{L, \max , e f f}=1.14(72 \%)$. With additional modifications of the propulsor integration and leading edge, the maximum effective lift coefficient is raised to $C_{L, \max , \text { eff }}=3.04$, yielding an increase by $\Delta C_{L, \text { max }, \text { eff }}=1.43(89 \%)$ compared to the 2 eProp configuration without thrust. While the results appear promising, it has to be noted that the high-lift system is not considered to be optimal, in particular for the 2 eProp configuration.

- In summary, the propulsive power requirement of the distributed propulsion configuration is between $-2.9 \%$ and $-3.3 \%$ lower compared to the one of the 2 eProp configuration exclusively based on aero-propulsive considerations. The initial assessment of the high-lift performance indicates that potential for additional propulsive power reduction in cruise flight due to wing size reduction exists.

Acknowledgements Financial support for this study has been provided by the Federal Ministry for Economic Affairs and Energy of Germany in the framework of LuFo V-3.

Funding Open Access funding enabled and organized by Projekt DEAL.

Open Access This article is licensed under a Creative Commons Attribution 4.0 International License, which permits use, sharing, adaptation, distribution and reproduction in any medium or format, as long as you give appropriate credit to the original author(s) and the source, provide a link to the Creative Commons licence, and indicate if changes were made. The images or other third party material in this article are included in the article's Creative Commons licence, unless indicated otherwise in a credit line to the material. If material is not included in 
the article's Creative Commons licence and your intended use is not permitted by statutory regulation or exceeds the permitted use, you will need to obtain permission directly from the copyright holder. To view a copy of this licence, visit http://creativecommons.org/licenses/by/4.0/.

\section{References}

1. Biser, S., Atanasov, G., Hepperle, M., Filipenko, M., Keller, D., Vechtel, D., Boll, M., Kastner, N., Noe, M.: Design Space Exploration Study and Optimization of a Distributed Turbo-Electric Propulsion System for a Regional Passenger Aircraft. [Online]. https://doi.org/10.2514/6.2020-3592

2. Loth, J., Loth, F.: Induced drag reduction with wing tip mounted propellers, ser. 2nd Applied Aerodynamics Conference, 1984. [Online]. https://doi.org/10.2514/6.1984-2149

3. Miranda, L., Brennan, J.: Aerodynamic effects of wingtipmounted propellers and turbines. [Online]. https://doi.org/10. 2514/6.1986-1802

4. J.C.P. Jr., Bartlett, G.R.: Evaluation of Installed Performance of a Wing-Tip-Mounted Pusher Turboprop on a Semispan Wing, NASA Technical Report TP-2739, (1987)

5. Sinnige, T., van Arnhem, N., Stokkermans, T.C.A., Eitelberg, G., Veldhuis, L.L.M.: Wingtip-mounted propellers: Aerodynamic analysis of interaction effects and comparison with conventional layout, J. Aircraft, vol. 56, no. 1, pp. 295-312, 2019. [Online]. https://doi.org/10.2514/1.C034978

6. Veldhuis, L.L.M.: Propeller Wing Aerodynamic Interference, Delft Univ. of Technology, Delft, The Netherlands, Ph.D. Thesis, (2005)

7. Borer, N.K., Derlaga, J.M., Deere, K.A., Carter, M.B., Viken, S., Patterson, M.D., Litherland, B., Stoll, A.: Comparison of AeroPropulsive Performance Predictions for Distributed Propulsion Configurations. [Online]. https://doi.org/10.2514/6.2017-0209

8. Patterson, M.D., Borer, N.K., German, B.: A Simple Method for High-Lift Propeller Conceptual Design. [Online]. https://doi.org/ 10.2514/6.2016-0770

9. Patterson, M.D., Derlaga, J.M., Borer, N.K.: High-Lift Propeller System Configuration Selection for NASA's SCEPTOR Distributed Electric Propulsion Flight Demonstrator. [Online]. https:// doi.org/10.2514/6.2016-3922

10. Gerhold, T.: Overview of the hybrid rans code tau, in MEGAFLOW - Numerical Flow Simulation for Aircraft Design, N. Kroll and J. K. Fassbender, Eds. Berlin, Heidelberg: Springer Berlin Heidelberg, 2005, pp. 81-92

11. Spalart, P., Allmaras, S.: A one-equation turbulence model for aerodynamic flows, no. 92-439. [Online]. https://doi.org/10. 2514/6.1992-439
12. Spalart, P., Shur, M.: On the sensitization of turbulence models to rotation and curvature, Aerospace Science and Technology, vol. 1, no. 5, pp. 297-302, (1997). [Online]. https://www.sciencedirect. com/science/article/pii/S1270963897900511

13. Glauert, H.: Airplane Propellers. Berlin, Heidelberg: Springer Berlin Heidelberg, 1935, pp. 169-360. [Online]. https://doi.org/ 10.1007/978-3-642-91487-4_3

14. Raichle, A.: Flux Conservative Discretization of the Actuator Disk Model as a Discontinuity Surface, Technical University Braunschweig, Braunschweig, Germany, Ph.D. Thesis, (2017)

15. Raichle, A., Melber-Wilkending, S., Himisch, J.: A new Actuator Disk Model for the TAU Code and application to a sailplane with a folding engine, in New Results in Numerical and Experimental Fluid Mechanics VI: Contributions to the 15th STAB/DGLR Symposium Darmstadt, Germany. Springer Berlin Heidelberg, 2008, vol. 96

16. Lenfers, C., Beck, N., Bauer, M.: Propeller and active high lift wing interaction in experiment and simulation. New Results Numer. Exp. Fluid Mech. X 132, 51-61 (2016)

17. Márquez Gutiérrez, C., Stuermer, A., Clemen, C., Grimminger, A.: Validation of Actuator Disk Simulations of CROR Propulsion Systems at Low-Speed Flight Conditions. [Online]. https://doi. org/10.2514/6.2012-2787

18. Spinner, S., Keller, D., Schnell, R., Trost, M.: A Blade Element Theory Based Actuator Disk Methodology for Modeling of Fan Engines in RANS Simulations. [Online]. https://doi.org/10. 2514/6.2020-2749

19. Hepperle, M.: Aspects of Distributed Propulsion - A View on Regional Aircraft. Stuttgart: Presentation held at Symposium "Elektrisches Fliegen", (2016), presentation

20. Larrabee, E.E.: Practical design of minimum induced loss propellers, SAE Transactions, vol. 88, pp. 2053-2062, (1979). [Online]. http://www.jstor.org/stable/44699041

21. Prandtl, L., Betz, A.: Vier Abhandlungen zur Hydrodynamik und Aerodynamik, Gottinger Klassiker der Strömungsmechanik, vol. 3, (2010)

22. Hepperle, M.: Inverse aerodynamic design procedure for propellers having a prescribed chord-length distribution, Journal of Aircraft, vol. 47, no. 6, pp. 1867-1872, 2010. [Online]. https://doi. org/10.2514/1.46535

23. CentaurSoft, Centaur hybrid grid generation system, Accessed 19th November (2012), phttp://www.centaursoft.com

Publisher's Note Springer Nature remains neutral with regard to jurisdictional claims in published maps and institutional affiliations. 